\title{
Editorial
}

\section{The Impact of SARS-CoV-2 on Inflammatory Bowel Disease}

\author{
Maria Manuela Estevinho ${ }^{a, b}$ Fernando Magro ${ }^{a, c-e}$ \\ ${ }^{a}$ Department of Biomedicine, Unit of Pharmacology and Therapeutics, Faculty of Medicine, University of Porto, \\ Porto, Portugal; ${ }^{b}$ Department of Gastroenterology, Centro Hospitalar Vila Nova de Gaia/Espinho, Vila Nova de Gaia, \\ Portugal; ' Department of Gastroenterology, Centro Hospitalar São João, Porto, Portugal; d MedlnUP, Center for \\ Drug Discovery and Innovative Medicines, Porto, Portugal; ' Unidade de Farmacologia Clínica, Centro Hospitalar \\ Universitário de São João, Porto, Portugal
}

Keywords

COVID-19 · Crohn's disease - Ulcerative colitis · SARS-CoV-2

\author{
O Impacto do Vírus SARS-CoV-2 na Doença \\ Inflamatória Intestinal
}

\section{Palavras Chave}

COVID-19 - Colite ulcerosa - Doença de Crohn . SARS-CoV-2

Inflammatory bowel disease (IBD), comprising Crohn's disease and ulcerative colitis, are estimated to affect up to $0.5 \%$ of the Western World population [1]. These diseases, characterized by periods of remission and relapse, are triggered by an inappropriate chronic immune response and, consequently, the therapeutic arsenal includes a wide range of immunosuppressive medications [2].

In December 2019, the world's eyes turned to Wuhan, China, the hometown of a novel coronavirus (SARS$\mathrm{CoV}-2$ ), which was soon identified as the causative agent

\section{KARGER}

karger@karger.com www.karger.com/pjg
(C) 2020 Sociedade Portuguesa de Gastrenterologia Published by S. Karger AG, Basel

Karcer

Upen access

This article is licensed under the Creative Commons AttributionNonCommercial-NoDerivatives 4.0 International License (CC BYNC-ND) (http://www.karger.com/Services/OpenAccessLicense) Usage and distribution for commercial purposes as well as any distribution of modified material requires written permission. of an emergent respiratory illness entitled the "2019 coronavirus disease" (COVID-19) [3]. The number of COVID-19 cases mushroomed quickly, posing a global public health emergency [4]. At the time of this writing, this pandemic affected more than 2.2 million people worldwide, accounting for over 145,000 deaths, numbers that continue to rise sharply [5]. Notwithstanding, in spite of the high transmission capacity, more than $80 \%$ of the patients have mild disease [6]. The risk factors for more severe illness are older age and underlying comorbidities, including diabetes, lung disease, and cardiovascular disease [7]. COVID-19 mortality is approximately $3.4 \%$, in comparison to $1.1 \%$ for influenza, $9.6 \%$ for severe acute respiratory syndrome (SARS), and $34.4 \%$ for the Middle East respiratory syndrome (MERS) [8]. Nonetheless, it is important to take into account that severe and fatal cases may be overrepresented as milder and asymptomatic cases are likely underreported [6].

Worldwide, scientists urged to elucidate SARS-CoV-2 mechanisms in an attempt to recycle or develop the drug armamentarium. As reported for the SARS coronavirus, identified in February 2003, SARS-CoV-2 engages angiotensin-converting enzyme 2 (ACE-2) as the entry receptor $[4,9]$. This receptor is expressed at higher levels in 
alveolar lung cells but also in the esophageal epithelium and in absorptive enterocytes from ileum and colon [10]. Indeed, the ACE-2 receptor was reported to be important for intestinal homeostasis, and its disruption may lead to diarrhea - whose prevalence in COVID-19 patients is up to $30 \%$ [11]. Besides this, SARS-CoV-2 was identified in stomach, duodenal, and rectal biopsies, and in the stool samples of infected patients - where it may persist after it is no longer detected in sputum [12]. Together, these findings highlighted the possible fecal-oral transmission. However, whether the virus in stool remains infectious and whether this route is clinically relevant remains unknown. Similarly, currently, there is no evidence supporting that SARS-CoV-2 infection is a cause of IBD flares. Even so, as some COVID-19 manifestations may mimic an IBD exacerbation, it is advised to test patients for SARS-CoV-2 before assuming the flare diagnosis.

Immunosuppressed patients, a category into which IBD patients fit, often present atypical presentations of viral diseases. However, the impact of immunosuppression on the susceptibility to COVID-19 is still unclear. Data reported thus far did not identify immunomodulator use as a risk factor for disease severity [7, 13], even though a decreased host immune surveillance could theoretically increase virus burden. Also, groups with relative immunosuppression, like pregnant women and HIV patients, do not appear to be more prone to complications [14]. Likewise, having Crohn's disease or ulcerative colitis does not increase the risk of becoming infected with SARS-CoV-2 or developing COVID-19 [3]; to date, 526 IBD patients were reported to be infected [15]. On the other hand, considering that systemic hyperinflammation may be a driver of COVID-19 severity, it could be hypothesized that patients under immunosuppressive treatment could have milder disease [16].

In this context, there is no evidence supporting the prophylactic suspension or dose adjustment of immunosuppressive or biologic medication in patients without SARS-CoV-2, as recommended by the European Crohn's and Colitis Organization [17] and the International Organization for the study of IBD [3]. Therefore, priority must be given the achievement and maintenance of IBD remission, and patients should continue drug infusions, as the risk of flares outweighs the probability of contracting coronavirus. Two cautious exceptions are: (i) patients under high-dose steroids ( $>20 \mathrm{mg} /$ day), where tapering must be as quickly as possible ( $\sim 10 \mathrm{mg} /$ week), or (ii) patients receiving combination therapy with biologics and immunomodulators, where the decision to reduce the immunosuppressor dose must be based on a case-by-case basis $[3,18]$. Notwithstanding, as it happens for all medical conditions, IBD management faces unprecedented challenges. In order to avoid any potential loss of followup, virtual clinical appointments must be conducted whenever possible, yet routine blood assessments may be deferred [13].

Different managements are advised in 2 different contexts: (i) when the IBD patient tested positive for SARSCoV-2 but is still asymptomatic; and (ii) when the patient has SARS-CoV-2 and develops COVID-19. In both cases, aminosalicylate therapy may be continued $[3,17,18]$. It is still uncertain whether budesonide, antitumor necrosis factor, vedolizumab, or ustekinumab should be stopped in asymptomatic patients, yet evidence suggests that in COVID-19 patients the 2 latter biologics should be suspended. On the other hand, thiopurines (azathioprine or 6-mercaptopurine), methotrexate, and tofacitinib must be suspended in patients infected with SARS-CoV-2 regardless of the presence of symptoms [3].

In case a patient stopped IBD medication, because he had tested positive for SARS-CoV-2 or had developed COVID-19, the timing for treatment restart is not consensual. Some experts advise that treatment must be resumed after symptoms have completely vanished, or after 2 weeks in patients who kept asymptomatic [3]. On the other hand, others recommend that in COVID-19 patients drugs can just be restarted after 2 negative polymerase chain reaction tests [18].

In addition, considering the possibility of a fecal-oral route, the fact that SARS-CoV-2 may be transmittable by surfaces or objects and that aerosolization during invasive procedures may promote spread through the airborne route [19], all elective endoscopies and surgeries must be postponed. In case of emergent procedures, it is advisable, when possible, to test patients for SARS-CoV-2 [13]. Besides this, whenever a respiratory infection is suspected, procedures must be performed in a negative pressure room, with a 30-min interval among one patient's exit and the entrance of the next [19]. Surely, this recommendation is not applicable in many settings. In this regard, others suggested that after an endoscopy, windows should be opened and at least $1 \mathrm{~h}$ should pass before admitting the next patient [20].

In conclusion, in the current health, social, and political context, it is imperious to temporarily redefine the standards of care and to restrict the number of patients attending the hospital, prioritizing telemedicine. In spite of that, IBD patients with flares or those coming for infusions or drug collection are advised to go to their IBD center. 


\section{Disclosure Statement}

Fernando Magro served as speaker and received honoraria from Merck Sharp \& Dohme, Abbvie, Vifor, Falk, Laboratórios Vitória, Ferring, Hospira, and Biogen. Maria Manuela Estevinho has no conflict of interests to disclose.
Funding Sources

The study was not supported.

\section{Author Contributions}

Maria Manuela Estevinho wrote the draft; Fernando Magro supervised and performed a critical revision.

\section{References}

1 Estevinho MM, Afonso J, Rosa I, Lago P, Trindade E, Correia L, et al.; GEDII [Portuguese IBD Group]. Placebo effect on the health-related quality of life of inflammatory bowel disease patients: A systematic review with meta-analysis. J Crohn's Colitis. 2018 Nov;12(10):1232-44.

2 Beaugerie L, Kirchgesner J. Balancing Benefit vs Risk of Immunosuppressive Therapy for Individual Patients With Inflammatory Bowel Diseases. Clin Gastroenterol Hepatol. 2019 Feb;17(3):370-9.

3 Rubin DT, Abreu MT, Rai V, Siegel CA; International Organization for the Study of Inflammatory Bowel Disease. Management of Patients with Crohn's Disease and Ulcerative Colitis During the COVID-19 Pandemic: Results of an International Meeting. Gastroenterology. 2020, DOI: 10.1053/j.gastro.2020. 04.002 .

4 Hoffmann M, Kleine-Weber H, Schroeder S, Krüger N, Herrler T, Erichsen S, et al. SARSCoV-2 Cell Entry Depends on ACE2 and TMPRSS2 and Is Blocked by a Clinically Proven Protease Inhibitor. Cell. 2020 Apr;181(2): 271-280.e8.

5 Worldometer's real-time data on COVID-19 [Internet]. 2020 [cited 2020 Apr 17]. Available from: https://www.worldometers.info/ coronavirus/.

6 Danese S, Cecconi M, Spinelli A. Management of IBD during the COVID-19 outbreak: resetting clinical priorities. Nat Rev Gastroenterol Hepatol. 2020, DOI: 10.1038/s41575020-0294-8.
7 Guan WJ, Ni ZY, Hu Y, Liang WH, Ou CQ, He JX, et al.; China Medical Treatment Expert Group for Covid-19. Clinical Characteristics of Coronavirus Disease 2019 in China. N Engl J Med. 2020, DOI: 10.1056/NEJMoa2002032.

8 Sohrabi C, Alsafi Z, O'Neill N, Khan M, Kerwan A, Al-Jabir A, et al. World Health Organization declares global emergency: A review of the 2019 novel coronavirus (COVID-19). Int J Surg. 2020 Apr;76:71-6.

9 Zhou P, Yang XL, Wang XG, Hu B, Zhang L, Zhang $\mathrm{W}$, et al. A pneumonia outbreak associated with a new coronavirus of probable bat origin. Nature. 2020 Mar;579(7798):270-3.

10 Gu J, Han B, Wang J. COVID-19: Gastrointestinal Manifestations and Potential FecalOral Transmission. Gastroenterology. 2020, DOI: 10.1053/j.gastro.2020.02.054.

11 Liang W, Feng Z, Rao S, Xiao C, Xue X, Lin Z, et al. Diarrhoea may be underestimated: a missing link in 2019 novel coronavirus. Gut. 2020, DOI: 10.1136/gutjnl-2020-320832.

12 Xiao F, Tang M, Zheng X, Liu Y, Li X, Shan H. Evidence for Gastrointestinal Infection of SARS-CoV-2. Gastroenterology. 2020, DOI: 10.1053/j.gastro.2020.02.055.

13 Magro F, Abreu C, Rahier J. The daily impact of COVID-19 in gastroenterology. United Eur Gastroenterol J. 2020, DOI: 10.1177/ 2050640620920157.

14 Comment on COVID-19 from the British HIV Association (BHIVA) [Internet]. 2020 [cited 2020 Apr 15]. Available from: https:// www.bhiva.org/comment-on-COVID19-from-BHIVA.
15 Surveillance Epidemiology of Coronavirus under Research Exclusion (SECURE-IBD) Database [Internet]. 2020. Available from: https://covidibd.org.

16 Ritchie AI, Singanayagam A. Immunosuppression for hyperinflammation in COVID-19: a double-edged sword? Lancet. 2020 Apr;395(10230):1111.

17 European Crohn's and Colitis Organisation recommendations on COVID-19 [Internet]. 2020 [cited 2020 Apr 15]. Available from: https://ecco-ibd.eu/publications/covid-19. html.

18 BSG expanded consensus advice for the management of IBD during the COVID-19 pandemic [Internet]. 2020 [cited 2020 Apr 14]. Available from: https://www.bsg.org.uk/covid-19-advice/bsg-advice-for-managementof-inflammatory-bowel-diseases-during-thecovid-19-pandemic/.

19 Lui RN, Wong SH, Sánchez-Luna SA, Pellino G, Bollipo S, Wong MY, et al. Overview of guidance for endoscopy during the coronavirus disease 2019 pandemic. J Gastroenterol Hepatol. 2020, DOI: 10.1111/jgh.15053.

20 Repici A, Maselli R, Colombo M, Gabbiadini R, Spadaccini M, Anderloni A, et al. Coronavirus (COVID-19) outbreak: what the department of endoscopy should know. Gastrointest Endosc. 2020, DOI: 10.1016/j.gie.2020. 03.019 . 